\title{
Stability issues in presence variable distributed generation into radial distribution network
}

\author{
Yuli Asmi Rahman ${ }^{1 *}$, Agus Siswanto ${ }^{2}$, and Irwan Mahmudi ${ }^{1}$ \\ ${ }^{1}$ Electrical Engineering Department, Tadulako University, 94119 Palu, Indonesia \\ ${ }^{2}$ Electrical Engineering Department, 17 Agustus 1945 University, 45135 Cirebon, Indonesia
}

\begin{abstract}
Related to environmental issues resulting from the use of traditional energy sources, drive usage of renewable energy is increasing. Changes in the structure of the network will certainly affect the changes in voltage stability. In this paper, discuss the impact of the stability after distributed generation penetration whose its output intermittent relatively. The simulation based PSAT software and tested into IEEE 30 bus system. Observation of voltage deviation and SVSI-index on some load buses in conditions before and after integration of wind generation. Load condition is a very determining factor of bus voltage stability index. This relates to the active power and reactive power needs that must be injected by DG penetration.
\end{abstract}

\section{Introduction}

An increase in the demand for loads in electrical power systems is a problem faced mainly in direct distribution networks with consumers. The need for additional power generation capacity, progress in power deregulation and utility restructuring and tight constraints on the construction of new transmission lines encourage interest in Distributed Generation (DG).

DG can be derived from both conventional and renewable energy sources. Currently, promising renewable energy sources for DG applications are photovoltaic (PV), microhydro, wind energy conversion system, geothermal energy, and so on. DG has a generating power range of 1-300 MW [1]. DG placement of pair size-location properly of the impact on the reduction of operating loss and operating cost at peak load, improvement of voltage profile and load factor, and increased reliability and stability of the system [2, 3]. Heavy demands and changed system configuration include integration of DG, and they were taken the role in system stability. Stability analysis is necessary to be pondered in the expansion and operation of electrical power systems.

In this study, to observe the impact of stability resulting from the integration of DG renewable energy, the study conducted by wind generation with different level penetration, DG location and load fluctuation. Stability analysis in this paper is done by using a static analysis approach. Various indicators for analyzing voltage stability in the literature are divided into three main groups [4]: line VSIs, bus VSIs, and VSIs overalls. In this paper,

${ }^{1}$ Corresponding author: asmi_yuli81@yahoo.co.id 
voltage stability margin (VSM) and Simplified Voltage Stability Index (SVSI) indicators. VSM use to identify the weak bus as location DG placement because it calculates the weakest load bus of the power system properly [5]. The simplicity of SFVSI formula[6], indeed, computation only need voltage bus magnitude.

The proposed method was implemented in the IEEE 30 bus radial system using PSAT software. PSAT software display the bus voltage profile information before and after DG placement, as a result, optimal power load flow.

\section{Voltage stability assesment}

The ability of an electric power system to remain in equilibrium condition both during normal operation and after the interruption is defined as the stability of the electric power system [7]. The generator runs at synchronous speed when the condition is balanced. Load fluctuations include an increase and decrease will affect the electrical power output that simultaneously impacts the change of mechanical power prime movers. If prime mover mechanical power cannot adjust to load conditions then this condition is called an unstable system. Simulated interference on the system is done to analyze the voltage stability, especially the analysis of the system's ability to change the load. This analysis is categorized as steady-state stability with small disturbance stimulation.

The measurement of the proximity of the operating point to the voltage instability is validated by the value of the voltage stability index [8]. It indicates a possible limit for the system to become unstable under steady state conditions. Conventionally, to know the condition of the bus is observed through the P-V curve and the Q-V curve which depicted in Figure 1. The plot of the curve illustrates the relationship between power and voltage when subjected to load changes.

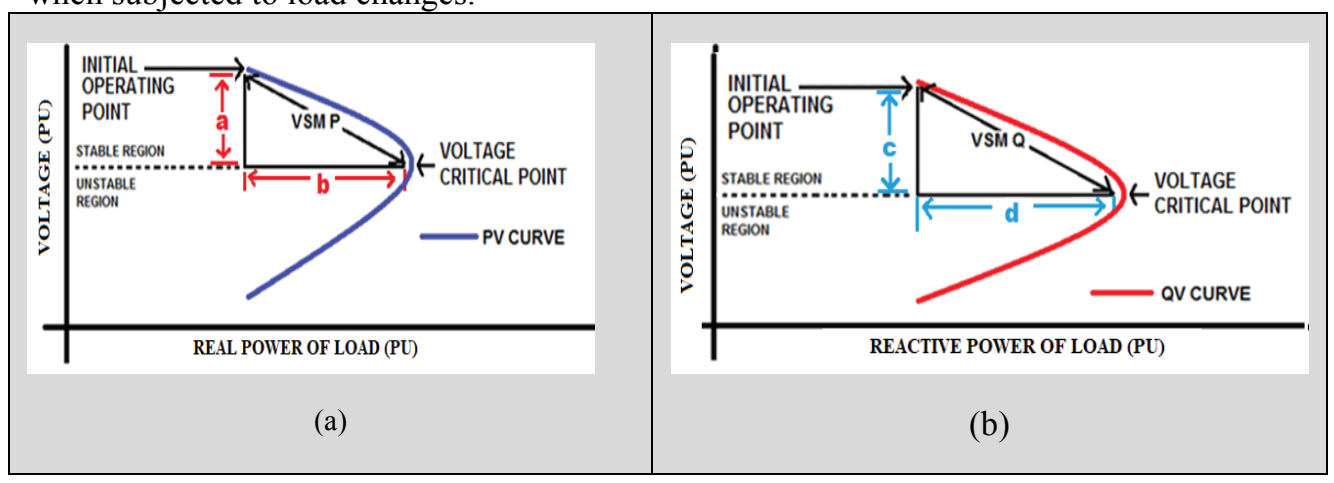

Fig. 1. (a) P-V Curve (b) Q-V Curve

Load changes affect the value of active or reactive power In the plot of the P-V curve and the Q-V curve, there is a knee point that identifies the stability limit value known as the Voltage Stability Margin (VSM). High or low VSM indicator value becomes a measure of the security level of the bus, where the higher the VSM value the bus is safe and vice versa[8].

\subsection{Voltage stability margin (VSM)}

VSM is divided into VSM (P) and VSM (Q). VSM (P) states the stability index on active power load and VSM (Q) for stability index at reactive load (Q). In Figure 1, let $P_{\text {initial }}$ and $\mathrm{Q}_{\text {initial }}$ is the values of each active and reactive load power at the initial operating point. $\mathrm{P}$ critical and Q critical load states are active and reactive power at the critical voltage points, 
respectively. The critical voltage in the system is the value of the bus voltage at the point of collapse voltage. The system will experience a collapse voltage when its value is less than zero, where the critical voltage value of VSM is zero. The equation (1) use to determine VSM:

$$
V S M=\frac{V_{\text {initial }}-V_{\text {critical }}}{V_{\text {critical }}}
$$

where $V_{\text {initial }}$ is bus voltage when normal operation and $V_{\text {critical }}$ is the bus voltage when voltage collapse like depicted in Figure 1.

\subsection{Simplified voltage stability index (SVSI)}

Some of voltage bus stability indicators in the reference are: voltage collapse prediction index $\left(\mathrm{VCPI}_{\text {bus }}\right)$ [9], L-index [10], voltage stability index ( $\left.\mathrm{VSI}_{\text {bus }}\right)$ [11], ZL=ZS ratio [12], and SVSI [13].

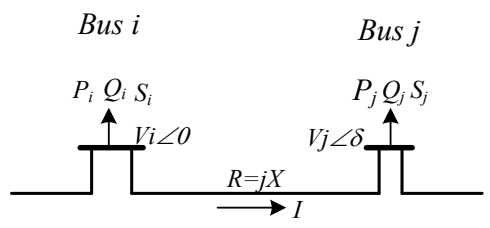

Fig.2. Representation of two bus power system

SVSI is a derivative of VSI index function which used to specify weak bust in the power system. Based on model in figure 2, definition of SVSI can be expressed as:

$$
S V S I_{i}=\frac{\Delta V_{i}}{\beta * V_{i}}
$$

Voltage deviation $\left(\Delta V_{i}\right)$ is difference between the nearest generator with load buses. The correction factor $\beta[9]$ is expressed as :

$$
\beta=1-\operatorname{Max}\left(\left|V_{m}\right|-|V l|\right)^{2}
$$

The SVSI threshold value for keeping the system stable refers to inequality:

$$
\operatorname{Max}(S V S I)<1
$$

The advantage of this indicator is applied to a large network. The calculation requires the parameters of the bus voltage of the sender and receiver side.

\section{Proposed Methods}

To observe the stability impact of DG, this used the IEEE 30 bus test system. This test case consists of one swing bus, five generator buses, and 24 load buses. Figure 3 is the layout of the schematic IEEE 30 bus system which built using the PSAT software. This is a Matlab toolbox for analysis and simulation of the electric power system. 
The DG used is a $50 \mathrm{MW}$ wind generator. Model of wind generator using doubly fed induction generator [14] with the penetration level of $15 \%$ and $30 \%$. The load fluctuations are considered as small disturbances in the system that affect the power system stability. Loads in variation overload by $40 \%$ and under load by $35 \%[13,15]$. Load flow is varied on active power load $(\mathrm{P})$, reactive power $(\mathrm{Q})$ and $\mathrm{P}+\mathrm{Q}$ load simultaneously.

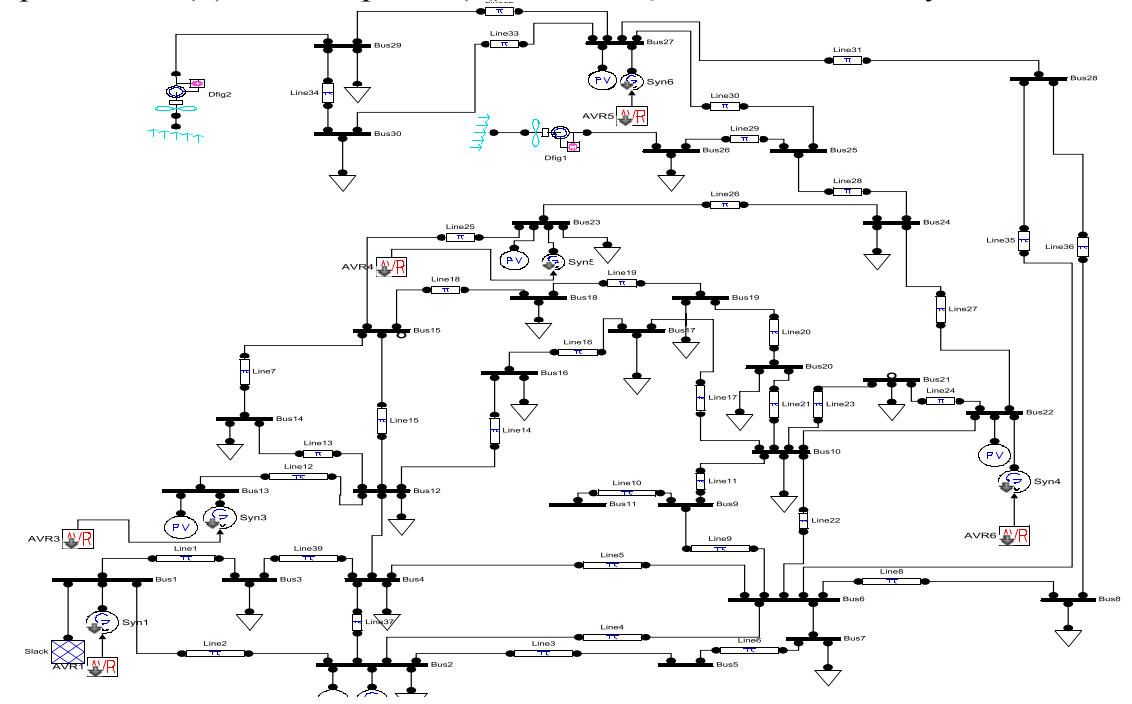

Fig. 3. PSAT model of IEEE 30 bus system connected wind generation

\section{Simulation and Results}

Using PSAT software, the simulation was tested on the IEEE 30- bus power system. This simulation aims to obtain the influence of DG integration on system stability using SVSI indicators. Active and reactive power load fluctuations provide a different SVSI response due to the bus voltage deviation generated. In testing, only three buses were selected for load fluctuations as shown in table 1 . Table 1 shows bus voltages, before and after penetration DG about $15 \%$ and $30 \%$ levels.

Table 1. Running load flow results for IEEE 30 bus system

\begin{tabular}{|c|c|c|c|}
\hline \multirow{2}{*}{ Bus } & \multicolumn{3}{|c|}{ Voltage deviation } \\
\cline { 2 - 4 } & \multirow{2}{*}{ Initial condition } & \multicolumn{2}{c|}{ Wind integration } \\
\cline { 3 - 4 } & & $\mathbf{1 5 \%}$ & $\mathbf{3 0 \%}$ \\
\hline 26 & 0.026 & 0028 & 0.035 \\
\hline 29 & 0.052 & 0.073 & 0.116 \\
\hline 30 & 0.054 & 0.081 & 0.128 \\
\hline
\end{tabular}

Based on the results of running flow by PSAT, the $\beta$ value obtained by 0.99374 calculated using equation (3). The calculation of voltage stability under different load conditions for different level penetration conditions is shown in figure 4. 


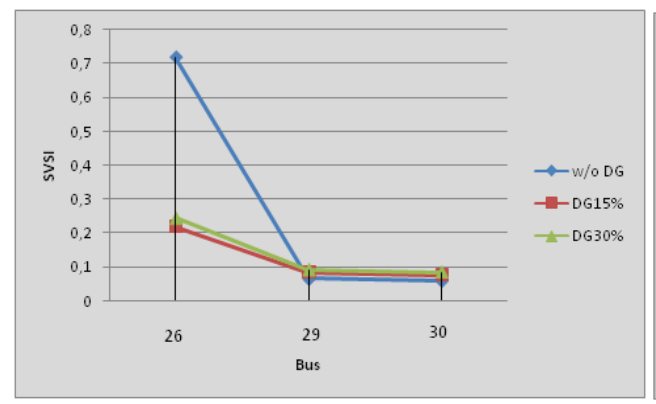

Fig. 4. (a)Voltage stability indices of heavy load

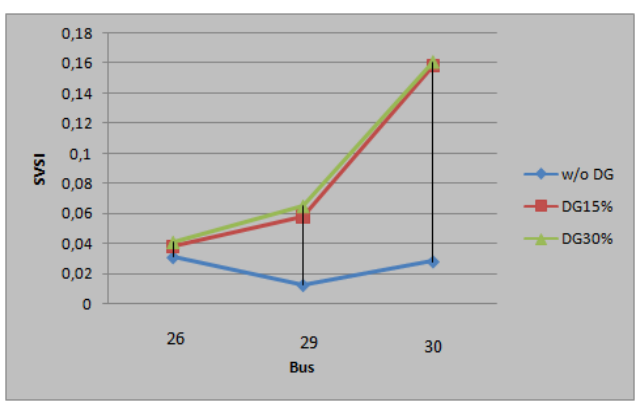

(b) Voltage stability indices of light load

The results show that the SVSI ratio on the conditions of base loading and heavy loading $(40 \%)$ ) looks the most critical on the bus 30 when $15 \%$ penetration of wind generator on buses 26 and 29. This value corrected due to active power contribution and reactive power of DG integration[16-17]. The addition of DG penetration level by $30 \%$ affects the shift in SVSI value which is increasingly towards a stable direction. Penetration DG improves the voltage deviation that corrects the value of $\beta$. Different conditions are obtained during light loads; the SVSI index has increased $1.33 \%$. This increase means that the condition of the bus leads to critical conditions. Increasing DG penetration level makes the bus voltage stability index does not make the system to the stable direction. This may be due to the active power and reactive power supplied by the grid-connected plant is sufficient. As a result, DG injected power causes an increased power loss effect resulting in a voltage drop across the load bus. This indicates that DG integration on the grid does not guarantee system stability will be better. There are load condition factors and DG sizes which determine the stability index as a measure of the system bus voltage stability.

\section{Conclusion}

In this paper, stability issues due to DG penetration on IEEE 30 bus systems are measured using SVSI and VSM. This study shows that DG integration affects the value of voltage stability. The load changes and the DG penetration level determine the critical value of the load bus. Need to assess DG size and location properly, because this determines active power and the reactive power injected into the system.

\section{The acknowledgements}

The authors are very grateful to Tadulako university through the technology research and higher education ministry to provide research grants for doctoral dissertation (097 / SP2H / LT / DRPM / 2018).

\section{References}

1. Yusran, A. Mochamad, and S. Adi, Optimization scheme of distributed generation installation growth considering network power quality, Journal of Theoretical and Applied Information Technology,vol.53, pp. 30-39 (2013) 
2. Wang, Z. and J. Wang, Review on Implementation and Assessment of Conservation Voltage Reduction. IEEE Transactions on Power Systems, 29, 3 (2014)

3. Rahman Y.A. et al, Evaluating the effect placement capacitor and distributed photovoltaic generation for power system losses minimization in radial distribution system, Engineering International Conference (EIC 2017), vol. 1941, p. 6 (2018)

4. Modarresi, J., E. Gholipour, and A. Khodabakhshian, A comprehensive review of the voltage stability indices. Renewable and Sustainable Energy Reviews, 63 (2016)

5. Ahmad Fateh Mohamad Nor, M.S., Aida Fazliana Abdul Kadir and Rosli Omar, Determining Voltage Stability Margin Values by Measuring the Hypotenuse Under PV and QV Curves, International Journal of Electrical Engineering and Applied Sciences, $1,1(2018)$

6. Oukennou, A. and A. Sandali. Assessment and analysis of Voltage Stability Indices in electrical network using PSAT Software. in 2016 Eighteenth International Middle East Power Systems Conference (MEPCON) (2016)

7. F. B. K. Mahmood. et al, Weakest location exploration in IEEE-14 bus system for voltage stability improvement using STATCOM, synchronous condenser and static capacitor International Conference on Electrical, Computer and Communication Engineering (ECCE) (2017)

8. Amjady, N. and M.R. Ansari, Improving voltage security assessment and ranking vulnerable buses with consideration of power system limits. International Journal of Electrical Power \& Energy Systems, vol.25, p. 10 (2003)

9. Balamourougan V, S.T., Sachdev MS, Technique for online prediction of voltage collapse IEE Proceeding Generation Transmission Distribution, 151, 453 (2004)

10. Kessel P, G.H., Estimating the voltage stability of a power system. IEEE Transaction Power Delivery. 346 (1986)

11. $\mathrm{MH}$, Haque, Use of local information to determine the distance to voltage collapse, International Power Engineering Conference (IPEC) p. 407-419 (2007)

12. A. Wiszniewski, New criteria of voltage stability margin for the purpose of load shedding ,IEEE Transaction Power Delivery, 22, 1367 (2007)

13. S. Pérez-Londoño, L.F.R., G. Olivar, A Simplified Voltage Stability Index (SVSI), Journal of electrical power and energy system, 83 (2014)

14. B. Babypriya , R.A., Modelling, Simulation and Analysis of Doubly Fed Induction Generator for Wind Turbine, Journal of electrical engineering, 60, 2 (2009)

15. Panda, R., et al. Impact analysis of wind power integration in existing power systems for study of voltage stability conditions, Eighteenth National Power Systems Conference (NPSC) (2014)

16. Siswanto, A., et al., Stability improvement of wind turbine penetrated using power system stabilizer (PSS) on South Sulawesi transmission system. Engineering International Conference (EIC2017), vol. 1941, p. 6 (2018)

17. Gunadin, I.C., Z. Muslimin, and A. Siswanto. Transient stability improvement using allocation power generation methods based on moment inertia, International Conference on Electrical Engineering and Informatics (ICELTICs). (2017) 